Communication

\title{
Quantitative Determination of 3-O-Acetyl-11-Keto- $\beta$-Boswellic Acid (AKBA) and Other Boswellic Acids in Boswellia sacra Flueck (syn. B. carteri Birdw) and Boswellia serrata Roxb
}

\author{
Giuseppe Mannino ${ }^{1}$, Andrea Occhipinti ${ }^{1,2}$ and Massimo E. Maffei ${ }^{1,2, *}$ \\ 1 Biosfered S.r.l., Innovation Centre, Academic Spin-Off of the University of Turin, Via Quarello 15/A, \\ Turin 10135, Italy; giuseppe.mannino@unito.it (G.M.); andrea.occhipinti@unito.it (A.O.) \\ 2 Department of Life Sciences and Systems Biology, Innovation Centre, University of Turin, \\ Via Quarello 15/A, Turin 10135, Italy \\ * Correspondence: massimo.maffei@unito.it; Tel.: +39-011-670-5967 \\ Academic Editor: Vassilios Roussis \\ Received: 29 July 2016; Accepted: 1 October 2016; Published: 6 October 2016
}

\begin{abstract}
Boswellia serrata and Boswellia sacra (syn. B. carteri) are important medicinal plants widely used for their content of bioactive lipophilic triterpenes. The qualitative and quantitative determination of boswellic acids (BAs) is important for their use in dietary supplements aimed to provide a support for osteoarthritic and inflammatory diseases. We used High Performance Liquid Chromatography (HPLC)-Diode Array Detector (DAD) coupled to ElectroSpray Ionization and tandem Mass Spectrometry (ESI-MS/MS) for the qualitative and quantitative determination of BAs extracted from the gum resins of B. sacra and B. serrata. Limit of detection (LOD), limit of quantification (LOQ), and Matrix Effect were assessed in order to validate quantitative data. Here we show that the BAs quantitative determination was $491.20 \mathrm{~g} \cdot \mathrm{kg}^{-1} \mathrm{~d}$. wt (49\%) in B. sacra and $295.25 \mathrm{~g} \cdot \mathrm{kg}^{-1} \mathrm{~d}$. wt $(30 \%)$ in B. serrata. Lower percentages of BAs content were obtained when BAs were expressed on the gum resin weight ( $29 \%$ and $16 \%$ for B. sacra and B. serrata, respectively). The content of Acetyl-11-Keto- $\beta$-Boswellic Acid (AKBA) was higher in $B . s a c r a\left(70.81 \mathrm{~g} \cdot \mathrm{kg}^{-1} \mathrm{~d}\right.$. wt; $7 \%$ ) than in $B$. serrata $\left(7.35 \mathrm{~g} \cdot \mathrm{kg}^{-1} \mathrm{~d}\right.$. wt; $\left.0.7 \%\right)$. Our results show that any claim of BAs content in either B. sacra or B. serrata gum resins equal to or higher than $70 \%$ or AKBA contents of $30 \%$ are simply unrealistic or based on a wrong quantitative determination.
\end{abstract}

Keywords: Acetyl-11-Keto- $\beta$-Boswellic Acid; 11-Keto-beta-Boswellic Acid; boswellic acids; standardization; Boswellia serrata; Boswellia sacra; HPLC-DAD-ESI-MS/MS

\section{Introduction}

The genus Boswellia (Burseraceae), comprises 25 species of trees and shrubs which are widely spread in Arabia, the north-eastern coast of Africa and India [1]. Since ancient times, the natural resin of Boswellia trees has been collected and used to produce the oleo gum resin, frankincense (olibanum). The gum resin is harvested from incisions made on the trunk of the tree and the darkening of resin droplets is an index of oxidation [2]. Among Boswellia species, only a few are of economic importance as a natural source of phytopharmaceutical compounds, including B. serrata Roxb. and B. sacra Flueck (syn. B. carteri Birdw, syn. B. undulatocrenata Engl.) [3-5].

B. serrata is used for the treatment of oxidative and inflammatory damage [2], rhinitis [6] asthma [7], age-related disorders [8], neurorecovery [9], arthritis [10], skin disorder [11], cancer [12], and against several human pathogenic and plant pathogenic fungi [13]. Recently, the pharmacological properties and clinical effectiveness of $B$. serrata have been studied systematically [3]. 
B. sacra oleo gum resin is used in the treatment of gastric and hepatic disorders [14], skin disorders [15], for its hepatoprotective activity [16], analgesic effect [4], antiglycation and antioxidant activities [17], tumor suppression [18], anticoagulation effects [19], antinflammatory activity [20], and cardioprotective effects [21].

The main constituents of B. serrata and B. sacra are volatile oils, composed of monoterpenes and sesquiterpenes [22,23], diterpenes including incensole, incensole acetate and cembrenol (serratol) [24], lipophilic pentacyclic triterpene acids of the oleanane-( $\alpha$-boswellic acids), ursane-( $\beta$-boswellic acids) and lupane-type (lupeolic acids), as well as an ether-insoluble fraction containing polysaccharides (arabinose, galactose, xylose) [25]. Among triterpenoids, bioactive boswellic acids are of particular interest, particularly 3-O-Acetyl-11-Keto- $\beta$-Boswellic Acid (AKBA), 11-Keto-beta-Boswellic Acid (KBA), and the various $\beta$-boswellic acids ( $\beta B A s)$, and $\alpha$-boswellic acids ( $\alpha$ BAs) and their esters. The analysis of these triterpenes is performed by different analytical methods including High Performance Thin Layer Chromatography (HPTLC) [26], although the most used methods are based on HPLC coupled to both photodiode array detection [27] and mass spectrometry detection [28]. In accordance with the spectral properties of the boswellic acids, their analysis is performed at three different wavelengths, $210 \mathrm{~nm}$ for $\alpha$ BAs, $\beta B$ As as well as lupeolic acid, $250 \mathrm{~nm}$ for AKBA and KBA, and $280 \mathrm{~nm}$ for 9,11-dehydro- $\alpha$ and - $\beta$-boswellic acids [27]. However, a precise identification and quantification of boswellic acids is usually obtained with liquid chromatography electrospray ionisation tandem mass spectrometry (LC-ESI-MS/MS) by using selected ion monitoring (SIM) detection [28].

In general, the total organic acids from B. serrata and B. sacra constitute approximately $65 \%-70 \%$ by weight of the total alcoholic extract. Of this fraction, approximately $25 \%$ is made of triterpenes. In market products, these percentages are often misinterpreted and it is not unusual to find claims of $70 \%$ boswellic acids content or $30 \%$ AKBA content, which is obviously misleading because the highest amounts so far reported of boswellic acids in B. serrata is about $140 \mathrm{mg} / \mathrm{g}$ (i.e., $14 \%$ ) and in B. sacra is about $190 \mathrm{mg} / \mathrm{g}$ (i.e., 19\%) [27]. Since both Boswellia extracts are used in several formulations, it is important to express unequivocally the "real content" of boswellic acids in both B. serrata and B. sacra. Therefore, the aim of this work is to provide a guideline for the accurate identification and quantification of boswellic acids in these two important Boswellia species by using HPLC-DAD-ESI-MS/MS.

\section{Results and Discussion}

\subsection{Identification of Boswellic Acids}

Gum resin of B. sacra and B. serrata were extracted using methanol in order to evaluate the total BAs content. The total yield for $B$. sacra methanolic extract was $598.88 \mathrm{~g} \cdot \mathrm{kg}^{-1}\left( \pm 11.40 \mathrm{~g} \cdot \mathrm{kg}^{-1}\right) \mathrm{gum}$ resin dry weight whereas the yield for $B$. serrata was $549.78 \mathrm{~g} \cdot \mathrm{kg}^{-1}\left( \pm 29.31 \mathrm{~g} \cdot \mathrm{kg}^{-1}\right)$ gum resin dry weight. The total recovery of methanolic extracts from $B$. sacra was $99.17 \%( \pm 1.93 \%)$, whereas the total recovery from $B$. serrata was $98.96 \%( \pm 1.97 \%)$. Our findings indicate that the total content of the lipophilic extracts (excluding the polysaccharide moiety of both species) never exceeded $60 \%$, in agreement with previous works $[27,29,30]$. By considering that the methanolic fraction contains several lipophilic compounds, including mono-, di- and triterpenes, it is evident that a claim of $70 \%$ BAs is not sustainable, being the BAs only a portion of the total methanolic extract.

In order to define the content and to identify the BAs present in the two Boswellia methanolic extracts, we performed HPLC-DAD-ESI-MS/MS analyses. Several BAs were present in both methanolic extracts. Table 1 reports the molecular mass and the fragmentation pattern of compounds identified in the methanolic extracts, whereas Figure 1 shows the chemical structure of the identified BAs. The identification of these compounds was achieved by both mass spectrometry and comparison with pure standards (see Supplementary Figure S1 for mass spectra of identified compounds and Supplementary Figure S2 for UV chromatograms). In both species, the main BAs were represented by $A K B A, K B A, \alpha B A, \beta B A$, acetyl $-\alpha B A(A-\alpha B A)$ and acetyl- $\beta B A$ (A- $\beta B A)$, in accordance with the literature data $[2,31,32]$. 
Table 1. Molecular mass and fragmentation pattern of compounds identified in the methanolic extracts of B. sacra and B. serrata.

\begin{tabular}{|c|c|c|c|c|c|c|}
\hline \multirow{2}{*}{\multicolumn{2}{|c|}{ Compounds }} & \multirow{2}{*}{ RT (min) } & \multirow{2}{*}[\mathbf{M}-\mathbf{H}]{$^{-}(m / z)$} & \multirow{2}{*}{ Ions $(m / z)$} & \multicolumn{2}{|c|}{ Occurrence in } \\
\hline & & & & & B. sacra & B. serrata \\
\hline 1 & 11-Keto-Ursolic acid & 24 & 469 & $451,407,391$ & $x$ & $x$ \\
\hline 2 & 11-Keto- $\beta$-boswellic acid & 25.8 & 469 & $451,407,391$ & $x$ & $x$ \\
\hline 3 & 3-O-Acetyl-11-keto- $\beta$-Boswellic Acid & 28.8 & 511 & 451,361 & $x$ & $x$ \\
\hline 4 & 3- $\alpha$-Hydroxy-7,24-dien-tirucallic acid & 34.5 & 455 & $453,437,373$ & & $x$ \\
\hline 5 & 3- $\alpha$-Hydroxy-8,24-dien-tirucallic acid & 36.5 & 455 & $453,437,373$ & $\mathrm{x}$ & $x$ \\
\hline 6 & 3- $\beta$-Hydroxy-7,24-dien-tirucallic acid & 39.4 & 455 & $453,437,373$ & & $x$ \\
\hline 7 & 3-O-Acetyl-oleanolic acid & 41 & 497 & 479,437 & $x$ & $x$ \\
\hline 8 & Lupeolic acid & 41.6 & 455 & 437,409 & & $\mathrm{x}$ \\
\hline 9 & 3-O-Acetyl-ursolic acid & 43.3 & 497 & 479,437 & $x$ & $x$ \\
\hline 10 & $\alpha$-Boswellic acid & 44.5 & 455 & $437,409,377$ & $x$ & $x$ \\
\hline 11 & $\beta$-Boswellic acid & 45 & 455 & $437,409,377$ & $x$ & $x$ \\
\hline 12 & 3-O-Acetyl- $\alpha$-boswellic acid & 52 & 497 & 459,437 & $x$ & $x$ \\
\hline 13 & 3-O-Acetyl- $\beta$-boswellic acid & 52.9 & 497 & $459,437,395$ & $x$ & $x$ \\
\hline
\end{tabular}

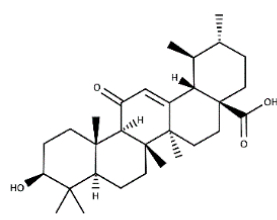

1

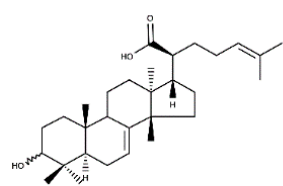

4

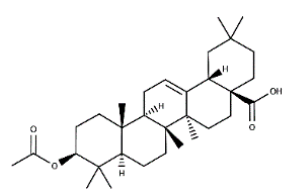

7

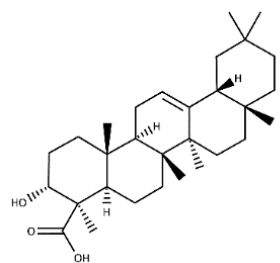

10

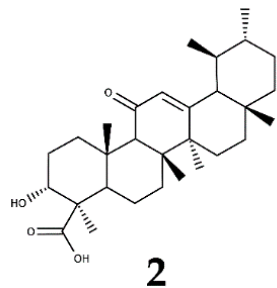

2

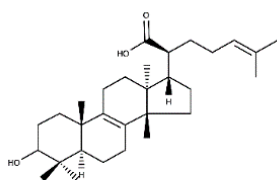

5

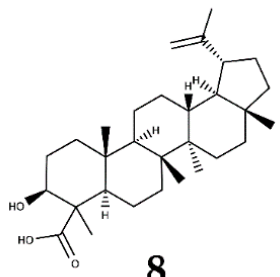

8

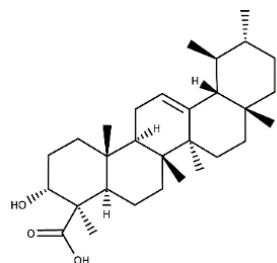

11

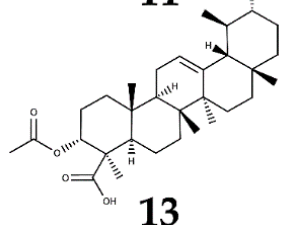

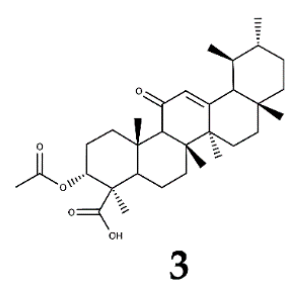

3

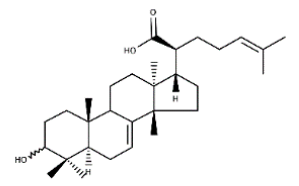

6

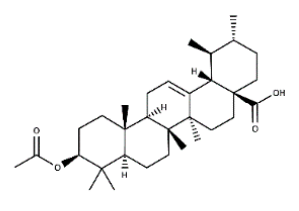

9

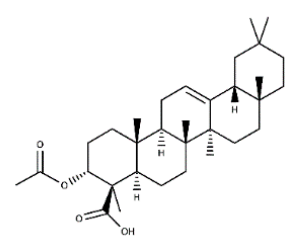

12

Figure 1. Chemical structure of the boswellic acids identified in Boswellia serrata and Boswellia sacra. Numbers correspond to compounds listed in Table 1. 


\subsection{Quantification of Boswellic Acids}

Table 2 shows for both species the quantitative determination of the main BAs. The total amount of the main BAs was statistically $(p<0.05)$ higher in B. sacra than in B. serrata. In B. sacra, the total amount of the main BAs in the methanolic extract was lower than $50 \%$ and this value was reduced to about $29 \%$ when the amount was considered in terms of the total gum resin dry weight (Table 2). In B. serrata the total content of the main BAs in the methanolic extract was lower than $30 \%$ and the value dropped to $16 \%$ when BAs were calculated in terms of the gum resin dry weight (Table 2 ). In both species, the major BAs were represented by $\alpha B A$ and $\beta B A$, in agreement with literature data [32]. A direct comparison between the two species shows that the contents of $B$. sacra AKBA (about 10 fold), $\alpha \mathrm{BA}(1.5$ fold $)$ and $\beta \mathrm{BA}(1.6$ fold $)$ were statistically $(p<0.05)$ higher than in $B$. serrata.

Table 2. Quantitative determination of boswellic acids in Boswellia sacra and Boswellia serrata by High Performance Liquid Chromatography-Diode Array Detector coupled to ElectroSpray Ionization and tandem Mass Spectrometry (HPLC-DAD-ESI-MS/MS), by using calibration curves from pure standards. Data are expressed as $\mathrm{g} \cdot \mathrm{kg}^{-1}$ gum resin dry weight. (Standard deviation), in the same row, different letters indicate significant $(p<0.05)$ differences.

\begin{tabular}{ccccc}
\hline \multirow{2}{*}{ Compound } & \multicolumn{2}{c}{ Boswellia sacra } & \multicolumn{2}{c}{ Boswellia serrata } \\
\cline { 2 - 5 } & $\begin{array}{c}\text { Content in the } \\
\text { Methanolic Extract }\end{array}$ & $\begin{array}{c}\text { Content in the } \\
\text { Gum Resin }\end{array}$ & $\begin{array}{c}\text { Content in the } \\
\text { Methanolic Extract }\end{array}$ & $\begin{array}{c}\text { Content in the } \\
\text { Gum Resin }\end{array}$ \\
\hline KBA & $35.50(1.26)^{\mathrm{a}}$ & $21.26(0.76)^{\mathrm{b}}$ & $34.62(2.57)^{\mathrm{a}}$ & $19.03(1.41)^{\mathrm{c}}$ \\
AKBA & $70.81(4.66)^{\mathrm{a}}$ & $42.41(2.79)^{\mathrm{b}}$ & $7.35(0.89)^{\mathrm{c}}$ & $4.04(0.49)^{\mathrm{d}}$ \\
$\alpha \mathrm{BA}$ & $184.34(11.27)^{\mathrm{a}}$ & $110.40(6.75)^{\mathrm{b}}$ & $126.00(7.77)^{\mathrm{b}}$ & $69.27(4.27)^{\mathrm{c}}$ \\
$\beta$ BA & $186.19(4.98)^{\mathrm{a}}$ & $111.50(2.98)^{\mathrm{b}}$ & $113.21(7.37)^{\mathrm{c}}$ & $62.24(4.06)^{\mathrm{c}}$ \\
$\mathrm{A}-\alpha \mathrm{BA}$ & $5.40(0.35)^{\mathrm{a}}$ & $3.23(0.21)^{\mathrm{b}}$ & $2.92(0.19)^{\mathrm{b}}$ & $1.60(0.11)^{\mathrm{c}}$ \\
A- $\beta \mathrm{BA}$ & $9.95(0.23)^{\mathrm{a}}$ & $5.96(0.14)^{\mathrm{b}}$ & $11.33(0.28)^{\mathrm{a}}$ & $6.23(0.15)^{\mathrm{b}}$ \\
Total & $491.20(14.75)^{\mathrm{a}}$ & $294.77(8.83)^{\mathrm{b}}$ & $295.25(23.00)^{\mathrm{b}}$ & $162.29(12.64)^{\mathrm{c}}$ \\
\hline
\end{tabular}

In order to validate the quantitative analyses reported in Table 2, we calculated the linearity and precision of the identified BAs standard curves, the detection limit (LOD), the quantification limit (LOQ) and the Matrix Effect (ME). Table 3 shows the validation results for the main identified BAs. All compounds showed a high $\mathrm{R}^{2}$ value, which indicates a high linearity in the calibration curves. The lowest LOD and LOQ values were found for A- $\beta B A$, followed by equal values for KBA and AKBA. The highest LOD and LOQ values were found for A- $\alpha$ BA. In order to complete the validation process, we assessed the ME, to assure that precision, selectivity and sensitivity were not compromised during HPLC-ESI-MS/MS analyses. The absolute ME was calculated by comparing the slope of matrix-matched standard curve with the slope of the standard calibration curve, according to [33]. Table 3 reports, for each species, the ME accuracy (expressed as percent values) of the main identified BAs. In $B$. sacra extracts, $\mathrm{KBA}(\mathrm{CV}=14.06)$ and $\mathrm{A}-\beta \mathrm{BA}(\mathrm{CV}=11.61)$ showed the highest percentage of accuracy, followed by AKBA $(C V=7.53)$ and $A-\alpha B A(C V=1.90)$. $\beta B A(C V=8.72)$ showed the lowest ME accuracy percentages. In $B$. serrata, the highest percentages of accuracy were found for $\alpha \mathrm{BA}$ $(\mathrm{CV}=0.22)$, followed by KBA $(\mathrm{CV}=14.13), \mathrm{A}-\alpha \mathrm{BA}(\mathrm{CV}=2.66)$ and $\mathrm{AKBA}(\mathrm{CV}=7.74)$.

Table 3. Validation of boswellic acids (BAs) quantitative analyses of methanolic extracts from B. sacra and B. serrata. (Standard deviation).

\begin{tabular}{ccccccc}
\hline Compound & Regression Equation & $\mathbf{R}^{\mathbf{2}}$ & $\mathbf{L O D} \boldsymbol{\mu g} \cdot \boldsymbol{\mu} \mathbf{L}^{-\mathbf{1}}$ & $\mathbf{L O Q} \boldsymbol{\mu g} \cdot \boldsymbol{\mu \mathbf { L } ^ { - 1 }}$ & ME B. sacra & ME $\boldsymbol{B}$. serrata \\
\hline KBA & $\mathrm{y}=13891880514 \mathrm{x}+180215436.7$ & 0.973 & 0.006 & 0.020 & $100.67(14.17)$ & $98.83(13.96)$ \\
AKBA & $\mathrm{y}=24732.09 \mathrm{x}-143.76$ & 0.997 & 0.006 & 0.021 & $99.91(7.53)$ & $91.53(7.08)$ \\
$\alpha$ BA & $\mathrm{y}=1349052089 \mathrm{x}+8552264.58$ & 0.989 & 0.008 & 0.028 & $88.52(9.75)$ & $139.80(0.31)$ \\
$\beta$ BA & $\mathrm{y}=1549451236 \mathrm{x}+1749204.16$ & 0.995 & 0.013 & 0.042 & $73.40(6.40)$ & $77.25(7.11)$ \\
A- $\alpha$ BA & $\mathrm{y}=9915.15 \mathrm{x}-127.16$ & 0.995 & 0.017 & 0.058 & $93.27(1.77)$ & $92.91(2.47)$ \\
A- $\beta$ BA & $\mathrm{y}=9179.53 \mathrm{x}-101.22$ & 0.995 & 0.003 & 0.010 & $100.23(11.64)$ & $90.70(8.74)$ \\
\hline
\end{tabular}

$\mathrm{R}^{2}$, coefficient of determination; LOD, Detection limit; LOQ, Quantification limit; ME, matrix effect, expressed as percentage of accuracy. 
Finally, Table 4 shows the recovery of the identified BAs from B. sacra and B. serrata methanolic extracts. In both species, the total recovery was higher than $98 \%$. In $B$. sacra, the highest recovery was found for $\mathrm{AKBA}$ and $\alpha \mathrm{BA}$, whereas in B. serrata the highest recovery was found for A- $\beta \mathrm{BA}$ and $\mathrm{A}-\alpha \mathrm{BA}$ (Table 4).

Table 4. Percentage of recovery of identified BAs from B. sacra and B. serrata methanolic extracts. Values are expressed as percentage of recovery.

\begin{tabular}{ccc}
\hline Compounds & B. sacra & B. serrata \\
\hline KBA & 96.53 & 99.06 \\
AKBA & 99.68 & 96.88 \\
$\alpha$ BA & 99.39 & 99.14 \\
$\beta B A$ & 98.75 & 97.13 \\
A- $\alpha$ BA & 88.71 & 99.38 \\
A- $\beta$ BA & 91.34 & 99.84 \\
Total & 98.68 & 98.41 \\
\hline
\end{tabular}

The quantitative determination of B. sacra and B. serrata BAs content and the validation of the quantitative chemical analysis show that any claim of BAs content in either B. sacra or B. serrata gum resins equal to or higher than $70 \%$ or $30 \%$ AKBA are simply unrealistic or based on a wrong quantitative determination. The same is true when the percentage of BAs is calculated in the methanolic extract.

\section{Materials and Methods}

\subsection{Plant Material and Chemicals}

Boswellia serrata Roxb. and Boswellia sacra Flueck gum resins were purchased from Bauer S.r.l. (Udine, Italy). The origin of B. sacra samples was from Ethiopia, whereas B. serrata samples originated from India. The gum resins were milled to coarse powder and used for all extractions. All chemicals were of analytical reagent-grade unless stated otherwise. Pure standards were purchased for the quantification by external calibration curves: 11-Keto- $\beta$-boswellic acid, $\alpha$-Boswellic acid and $\beta$-Boswellic acid (ExtraSynthese, Lyon, France), 3-O-Acetyl-11-keto- $\beta$-Boswellic Acid (Merck, Darmstadt, Germany), 3-O-Acetyl- $\alpha$-boswellic acid, 3-O-Acetyl- $\beta$-boswellic acid (Sigma-Aldrich, St. Louis, MO. USA).

\subsection{Solvent Extraction of Boswellia serrata and Boswellia sacra oleo Gum Resins}

One hundred grams of ground B. serrata and B. sacra oleo gum-resins were extracted with $1 \mathrm{~L}$ methanol (VWR International, Radnor, PA, USA) (extraction ratio 1:10 w/v). Samples were then placed on an orbital shaker for 5 days in the dark. Extracts were then filtered and the resin was rinsed with $400 \mathrm{~mL}$ of methanol. To evaluate the recovery of analyzed compounds, the exhaust gum resin was re-extracted with methanol as previously described. Samples were then concentrated by vacuum evaporation (Rotavapor, Büchi, Flawil, Switzerland). Concentrated extracts were then dried in a ventilated oven at $70{ }^{\circ} \mathrm{C}$ for $4 \mathrm{~h}$. The powdered extracts were stored at room temperature in the dark until chemical analysis. Extractions were performed in triplicate.

\subsection{Isolation and Quantification of Boswellic Acids by HPLC-DAD-ESI-MS/MS}

Boswellic acids were identified and quantified by liquid chromatography (1200 HPLC, Agilent Technologies, Santa Clara, CA, USA) equipped with a reverse phase column, Luna C18 (3 $\mu$, $150 \mathrm{~mm} \times 3.0 \mathrm{~mm}$, Phenomenex, Torrance, CA, USA). B. serrata and B. sacra powdered extracts were dissolved (30 mg. $\mathrm{mL}^{-1}$ ) in HPLC-grade methanol and properly diluted. The binary solvent system was: (A) MilliQ $\mathrm{H}_{2} \mathrm{O}$ (Millipore, Billerica, MA, USA):Methanol 50:50 containing $5 \mathrm{mM}$ ammonium acetate (Sigma-Aldrich, USA); and (B) Methanol:1-Propanol (VWR International, Radnor, PA, USA) 
80:20 containing $5 \mathrm{mM}$ ammonium acetate. The chromatographic separation was carried out at constant flow rate $\left(200 \mu \mathrm{L} \cdot \mathrm{min}^{-1}\right)$ with the following conditions: linear gradient from $30 \%$ to $50 \%$ of $\mathrm{B}$ in $2 \mathrm{~min}$, then $80 \%$ of B in $35 \mathrm{~min}$, then at $47 \mathrm{~min} \mathrm{~B}$ concentration was raised to $98 \%$. The concentration of solvent B was maintained at $98 \%$ for $6 \mathrm{~min}$. The initial mobile phase was re-established for $10 \mathrm{~min}$ before the next injection. The temperature of wellplate autosempler G1377A was set $4{ }^{\circ} \mathrm{C}$ while chromatography was carried out at constant temperature $\left(30^{\circ} \mathrm{C}\right)$ controlled by an Agilent $1100 \mathrm{HPLC}$ G1316A Column Compartment.

Tandem mass spectrometry analyses were performed with a 6330 Series Ion Trap LC-MS System (Agilent Technologies, USA) equipped with an electrospray ionization source (ESI) operating in negative mode. The flow rate of nitrogen was set $325^{\circ} \mathrm{C}$ and $5.0 \mathrm{~L} \cdot \mathrm{min}^{-1}$, while the Capillary Voltage was $1.5 \mathrm{kV}$. Helium was used as a collision gas.

Identification of Boswellia oleo gum resin compounds was performed by scan analyses with a 50-750 $\mathrm{m} / \mathrm{z}$ scan range and by monitoring the absorption at 210, 250 and $280 \mathrm{~nm}$. Quantitative analyses were performed by Multiple Reaction Monitoring (MRM) by monitoring the fragmentation of quasi-molecular ions for $\alpha \mathrm{BA}$ and $\beta \mathrm{BA}$ and KBA (Table 1) and by Diode Array Detector (DAD) at $250 \mathrm{~nm}$ for AKBA and $210 \mathrm{~nm}$ for A- $\alpha$ BA and A- $\beta$ BA. Quantification was performed by external calibration curves with pure standards dissolved in HPLC grade Methanol. Limit of Detections (LOD) and Limit of Quantifications (LOQ) for each compounds were determined as described in [34].

To evaluate the $\mathrm{ME}$ in the quantification of target compounds, B. serrata and B. sacra powdered extracts were dissolved $\left(30 \mathrm{mg} \cdot \mathrm{mL}^{-1}\right)$ in HPLC-grade methanol and properly diluted. These sample solutions were used to prepare the calibration curves in the presence of other extracted gum resin compounds [33]. The slope of standard curves obtained with the solvent (methanol) and in the extracts were used to compare the ME percentage $(\% \mathrm{ME}=$ Calibration Slope (sample $) /$ CalibrationSlope $\left._{(\text {standard })} \times 100\right)$. $100 \% \mathrm{ME}$ percentage indicates no $\mathrm{ME}$, a $\mathrm{ME} \%<100 \%$ indicates ionization suppression and a $\mathrm{ME} \%$ > $100 \%$ indicates ionization enhancement.

\section{Conclusions}

Boswellia sacra and Boswellia serrata extracts are widely used in pharmaceutical and nutraceutical preparations. The bioactivity of these Boswellia extracts is based on the content of BAs. Clearly, the dose of bioavailable BAs is central to the issue of Boswellia efficacy. Claims of $70 \%$ BAs or even $30 \%-40 \%$ AKBA are currently found, but this work confirms that the BAs content never exceeds $50 \%$ of the methanolic extract, whereas lower percentages are obtained when BAs are expressed in terms of the gum resin weight. Moreover, the highest percentage of AKBA found in B. sacra was below $8 \%$. Only analytical methods based on HPLC coupled to mass spectrometry allow the precise quantification and identification of BAs in Boswellia extracts, whereas other methods based only on HPLC or spectrophotometric methods do not sufficiently allow an accurate quantification of BAs. Therefore, we recommend LC-MS technology for BAs determination and quantification.

Supplementary Materials: The following are available online at http://www.mdpi.com/1420-3049/21/10/1329/s1, Figure S1: mass spectra of boswellic acids isolated in this study; Figure S2: UV chromatograms of boswellic acids isolated in this study.

Acknowledgments: This work was supported by the PhD Program in Pharmaceutical and Biomolecular Sciences of the University of Turin and by the Academic Spin-Off Biosfered S.r.l.

Author Contributions: M.E.M and A.O. conceived and designed the experiments; A.O. and G.M. performed the experiments; M.E.M. and A.O. analyzed the data; M.E.M. contributed reagents/materials/analysis tools; M.E.M. wrote the paper.

Conflicts of Interest: The authors declare no conflict of interest. 


\section{References}

1. Atta, U.R.; Naz, H.; Makhmoor, F.T.; Yasin, A.; Fatima, N.; Ngounou, F.N.; Kimbu, S.F.; Sondengam, B.L.; Choudhary, M.I. Bioactive constituents from Boswellia papyrifera. J. Nat. Prod. 2005, 68, 189-193. [CrossRef] [PubMed]

2. Siddiqui, M.Z. Boswellia serrata, a potential antiinflammatory agent: An overview. Indian J. Pharm. Sci. 2011, 73, 255-261. [PubMed]

3. Ernst, E. Frankincense: Systematic review. Brit. Med. J. 2008, 337, 1439-1441. [CrossRef] [PubMed]

4. Al-Harrasi, A.; Ali, L.; Hussain, J.; Rehman, N.U.; Mehjabeen; Ahmed, M.; Al-Rawahi, A. Analgesic effects of crude extracts and fractions of Omani frankincense obtained from traditional medicinal plant Boswellia sacra on animal models. Asian Pac. J. Trop. Med. 2014, 7, S485-S490. [CrossRef]

5. ThePlantList, Boswellia sacra Flueck. is an accepted name. Available online: http://www.theplantlist.org/ tpl1.1/record/kew-2680579 (accessed on July 20 2016).

6. Marogna, M.; Braidi, C.; Colombo, C.; Colombo, F.; Palumbo, L. A randomized controlled trial of a phytotherapic compound containing Boswellia serrata and bromeline for seasonal allergic rhinitis complicated by upper airways recurrent respiratory infections. J. Allergy Clin. Immun. 2015, 135, Ab271-Ab271. [CrossRef]

7. Soni, K.K.; Lawal, T.; Wicks, S.; Patel, U.; Mahady, G.B. Boswellia serrata and Ocimum sanctum extracts reduce inflammation in an ova-induced asthma model of BALB/c mice. Planta Med. 2015, 81, 879-879. [CrossRef]

8. Hosseini-Sharifabad, M.; Esfandiari, E. Effect of Boswellia serrata gum resin on the morphology of hippocampal CA1 pyramidal cells in aged rat. Anat Sci. Int. 2015, 90, 47-53. [CrossRef] [PubMed]

9. Moein, P.; Fard, S.A.; Asnaashari, A.; Baratian, H.; Barekatain, M.; Tavakoli, N.; Moein, H. The effect of Boswellia serrata on neurorecovery following diffuse axonal injury. Brain Injury 2013, 27, 1454-1460. [CrossRef] [PubMed]

10. Wang, H.; Zhang, C.N.; Wu, Y.; Ai, Y.; Lee, D.Y.W.; Dai, R.H. Comparative pharmacokinetic study of two boswellic acids in normal and arthritic rat plasma after oral administration of Boswellia serrata extract or Huo Luo Xiao Ling Dan by LC-MS. Biomed. Chromatogr. 2014, 28, 1402-1408. [CrossRef] [PubMed]

11. Togni, S.; Maramaldi, G.; Bonetta, A.; Giacomelli, L.; Pierro, F. Clinical evaluation of safety and efficacy of Boswellia-based cream for prevention of adjuvant radiotherapy skin damage in mammary carcinoma: A randomized placebo controlled trial. Eur. Rev. Med. Pharm. 2015, 19, 1338-1344.

12. Ahmed, H.; Abdel-Rahman, M.; Salem, F.E.; Shalby, A.; Lokman, M.S. Boswellia serrata and colon cancer: Evidence based approach for treatment. Planta Med. 2014, 80, 1545-1545. [CrossRef]

13. Gangwal, M.L.; Vardhan, D.K. Antifungal Studies of Volatile Constituents of Boswellia serrata. Asian J. Chem. 1995, 7, 675-676.

14. Asad, M.; Alhomoud, M. Proulcerogenic effect of water extract of Boswellia sacra oleo gum resin in rats. Pharm. Biol. 2016, 54, 225-230. [CrossRef] [PubMed]

15. Nardoni, S.; Giovanelli, S.; Pistelli, L.; Mugnaini, L.; Profili, G.; Pisseri, F.; Mancianti, F. In Vitro Activity of Twenty Commercially Available, Plant-Derived Essential Oils against Selected Dermatophyte Species. Nat. Prod. Commun. 2015, 10, 1473-1478. [PubMed]

16. Asad, M.; Alhumoud, M. Hepatoprotective effect and GC-MS analysis of traditionally used Boswellia sacra oleo gum resin (Frankincense) extract in rats. Afr. J. Tradit. Complement. 2015, 12, 1-5. [CrossRef]

17. Al-Harrasi, A.; Ali, L.; Ceniviva, E.; Al-Rawahi, A.; Hussain, J.; Hussain, H.; Rehman, N.U.; Abbas, G.; Al-Harrasi, R. Antiglycation and Antioxidant Activities and HPTLC Analysis of Boswellia sacra Oleogum Resin: The Sacred Frankincense. Trop. J. Pharm. Res. 2013, 12, 597-602. [CrossRef]

18. Suhail, M.M.; Wu, W.J.; Cao, A.; Mondalek, F.G.; Fung, K.M.; Shih, P.T.; Fang, Y.T.; Woolley, C.; Young, G.; Lin, H.K. Boswellia sacra essential oil induces tumor cell-specific apoptosis and suppresses tumor aggressiveness in cultured human breast cancer cells. BMC Complement. Altern. Med. 2011, 11. [CrossRef] [PubMed]

19. Pan, Y.N.; Liang, X.X.; Niu, L.Y.; Wang, Y.N.; Tong, X.; Hua, H.M.; Zheng, J.; Meng, D.Y.; Liu, X.Q. Comparative studies of pharmacokinetics and anticoagulatory effect in rats after oral administration of Frankincense and its processed products. J. Ethnopharmacol. 2015, 172, 118-123. [CrossRef] [PubMed]

20. Banno, N.; Akihisa, T.; Yasukawa, K.; Tokuda, H.; Tabata, K.; Nakamura, Y.; Nishimura, R.; Kimura, Y.; Suzuki, T. Anti-inflammatory activities of the triterpene acids from the resin of Boswellia carteri. J. Ethnopharmacol. 2006, 107, 249-253. [CrossRef] [PubMed] 
21. Zaki, A.A.; Hashish, N.E.; Amer, M.A.; Lahloub, M.F. Cardioprotective and antioxidant effects of oleogum resin "Olibanum" from Boswellia carteri Birdw. (Bursearceae). Chin. J. Nat. Med. 2014, 12, 345-350. [CrossRef]

22. Niebler, J.; Buttner, A. Unraveling the smell of frankincense: Identification of potent odorants in Boswellia sacra resin and pyrolysate. Abs. Pap. Am. Chem. Soc. 2014, 248, 159.

23. Singh, B.; Kumar, R.; Bhandari, S.; Pathania, S.; Lal, B. Volatile constituents of natural Boswellia serrata oleo-gum-resin and commercial samples. Flav. Fragr. J. 2007, 22, 145-147. [CrossRef]

24. Pollastro, F.; Golin, S.; Chianese, G.; Putra, M.Y.; Moriello, A.S.; de Petrocellis, L.; Garcia, V.; Munoz, E.; Taglialatela-Scafati, O.; Appendino, G. Neuractive and anti-inflammatory Frankincense cembranes: A structure-activity study. J. Nat. Prod. 2016, 79, 1762-1768. [CrossRef] [PubMed]

25. Herrmann, A.; Lechtenberg, M.; Hensel, A. Comparative isolation and structural investigations of polysaccharides from Boswellia serrata ROXB and Boswellia carteri BIRDW. Planta Med. 2007, 73, 815-815. [CrossRef]

26. Krohn, K.; Rao, M.S.; Raman, N.V.; Khalilullah, M. High-performance thin layer chromatographic analysis of anti-inflammatory triterpenoids from Boswellia serrata Roxb. Phytochem. Anal. 2001, 12, 374-376. [CrossRef] [PubMed]

27. Buchele, B.; Zugmaier, W.; Simmet, T. Analysis of pentacyclic triterpenic acids from frankincense gum resins and related phytopharmaceuticals by high-performance liquid chromatography. Identification of lupeolic acid, a novel pentacyclic triterpene. J. Chromatogr. B-Anal. Technol. Biomed. Life Sci. 2003, 791, 21-30. [CrossRef]

28. Frank, A.; Unger, M. Analysis of frankincense from various Boswellia species with inhibitory activity on human drug metabolising cytochrome P450 enzymes using liquid chromatography mass spectrometry after automated on-line extraction. J. Chromatogr. A 2006, 1112, 255-262. [CrossRef] [PubMed]

29. Buchele, B.; Zugmaier, W.; Genze, F.; Simmet, T. High-performance liquid chromatographic determination of acetyl-11-keto-alpha-boswellic acid, a novel pentacyclic triterpenoid, in plasma using a fluorinated stationary phase and photodiode array detection: Application in pharmacokinetic studies. J. Chromatogr. B 2005, 829, 144-148. [CrossRef] [PubMed]

30. Buchele, B.; Simmet, T. Analysis of 12 different pentacyclic triterpenic acids from frankincense in human plasma by high-performance liquid chromatography and photodiode array detection. J. Chromatogr. B 2003, 795, 355-362. [CrossRef]

31. Paul, M.; Bruning, G.; Bergmann, J.; Jauch, J. A Thin-layer Chromatography Method for the Identification of Three Different Olibanum Resins (Boswellia serrata, Boswellia papyrifera and Boswellia carterii, respectively, Boswellia sacra). Phytochem. Anal. 2012, 23, 184-189. [CrossRef] [PubMed]

32. Shah, B.A.; Qazi, G.N.; Taneja, S.C. Boswellic acids: a group of medicinally important compounds. Nat. Prod. Rep. 2009, 26, 72-89. [CrossRef]

33. Villagrasa, M.; Guillamon, M.; Eljarrat, E.; Barcelo, D. Matrix effect in liquid chromatography-electrospray ionization mass spectrometry analysis of benzoxazinoid derivatives in plant material. J. Chromatogr. A 2007, 1157, 108-114. [CrossRef] [PubMed]

34. Validation of analytical procedures: Text and Methodology Q2(R1). Available online: http://www.ich.org/ fileadmin/Public_Web_Site/ICH_Products/Guidelines/Quality/Q2_R1/Step4/Q2_R1_Guideline.pdf (accessed on 27 July 2016).

Sample Availability: Samples of the compounds are not available.

(c) 2016 by the authors; licensee MDPI, Basel, Switzerland. This article is an open access article distributed under the terms and conditions of the Creative Commons Attribution (CC-BY) license (http:/ / creativecommons.org/licenses/by/4.0/). 